\title{
Assessment of Nurse, Work Related Motivators in Patient Care in Mombasa County
}

\author{
Moses Mutua ${ }^{1 *} \quad$ Dr. Agnes Mutinda \\ Department of Nursing Kenya Methodist University P.o box 89983-80100 Mombasa
}

\begin{abstract}
The world over, Nursing role is vital in all health systems as they spend a considerable amount of time monitoring patients and are therefore instrumental in determining patient care. The objective of this study is to investigate work related motivators for better patient outcomes in Mombasa County. According to Maslow and Herzberg a validated instrument addressing three work-related motivators such as job attributes, remuneration and co-workers was used. The job attributes factors are: authority, creativity opportunities, clear duties, job control, and decision-making. The remuneration factors are: salary and continuous education. A large number of nurses agreed there is teamwork, majority have received no rewards and $93.3 \%$ have not received recognition. Improved teamwork, recognition and rewards improve nurse morale and subsequently improve patient care. Most nurse rated supervisor and teamwork to be well improved, while appreciation and working conditions were rated poorly. Nurses listed their greatest motivators to be remuneration, job attributes, and coworkers. Majority of the nurses agree that if motivated they would perform better patient care. Job attributes, remuneration and coworkers correlation was rated ( $\mathrm{r}=0.740 .87$ and 0.64$)$ showed a strong positive correlation towards nursing motivation. Chi square was used to test the relationship among variables job attributes $(\mathrm{p}=0.00)$, remuneration $(\mathrm{p}=0.00)$ and coworker $(\mathrm{p}=0.00)$ this showed a statistical significant relationship among variables. The study therefore concluded that nurses are motivated more by, remuneration: salary and continuous professional training. Other motivators were identified as job attributes (authority, creativity and decision making) and coworkers (teamwork, appreciation and supervisor fairness). The study therefore recommends that nurses need to carry out nursing duties with authority and creativity, involving them in decision making on decision affecting them. A review of salaries and opportunities to make money on the job are key in motivating nurses.
\end{abstract}

Keywords: Motivation, patient outcomes, job attributes, remuneration

DOI: $10.7176 / \mathrm{JHMN} / 97-04$

Publication date: January $31^{\text {st }} 2022$

\section{Introduction}

Health workers form the backbone of any health system. Their motivation can significantly improve patient outcomes (4). Nurses form the biggest percentage of the health workforce and are involved with day to day direct patient care. A well-motivated nursing workforce will greatly improve human resources for health and in turn improve patient outcomes (3).

Describing a global health workforce crisis in 57 countries, 36 in sub-Saharan Africa, there is an estimated shortfall of $1.5 \mathrm{~m}$ health workers in Africa alone. Research has demonstrated that a more highly educated and motivated nursing workforce not only improves patient safety and quality of care but saves lives (6).

In sub-Saharan Africa, lack of motivation has been cited as causes of poor healthcare quality and outcomes (5). In studies carried out in Benin and Tanzania showed that both financial and non-financial incentives played a key role in motivating nurses.

Based on the active nursing workforce, Kenya has a nurse to population ratio of 103.4 nurses per 100,000 compared to the WHO recommendation of 250 health workers per 100,000. (2). In 2004, Kenya's doctor to nurse ratio was 1 doctor for 8.24 nurses.

Nurses comprise a substantial portion of the health workforce in Kenya and are key in establishing better patient outcomes. In Kenya the annual intake of new students almost tripled from 1,545 in 2010 to 4,294 in 2015.For the public, parastatal and faith-based institutions reporting, there are a total of 19,591 nurses deployed at 4,187 health facilities across Kenya. Based on available data 2008-2015, 1482 nurses left the public sector.

The causes of public sector nursing attrition include retirement $(12 \%)$, death $(13 \%)$, dismissal $(9 \%)$, resignation (10\%) and transfer $(6 \%)$, migration (43\%). The majority of applications to migrate were to the United States (62\%). Although nurse motivation is a significant element of health systems' performance, it is largely understudied. A validated instrument developed by Maslow and addressing three work-related motivators (job attributes, remuneration and co-workers) was used. The job attributes factor encompasses items: authority, creativity opportunities, clear duties, job control, and decision-making. The remuneration factor encompasses: salary and continuous education. The co-workers factor encompasses: teamwork, appreciation, supervisor and fairness (1).

Mombasa has a 43.4:100000 ratio of nurses to population. The causes of public sector nursing attrition include retirement $(7 \%)$, death $(12 \%)$, dismissal $(5 \%)$, resignation $(10 \%)$ and transfer $(6 \%)$ with migrations 
hitting a high of $(60 \%)$. Factors attributed to the migration of nurses are poor motivation $(40 \%)(2)$ With more nurses leaving, it has a significant effect on patient outcomes. Nurses in coast general hospital have frequently complained of the low staff motivation versus growing patient numbers.

\section{Methods}

\subsection{Instrument}

According to Maslow and Herzberg a validated instrument addressing three work-related motivators such as job attributes, remuneration and co-workers was used. The job attributes factors are: authority, creativity opportunities, clear duties, job control, and decision-making. The remuneration factors are: salary and continuous education. The co-workers factors are: teamwork, appreciation, supervisor and fairness.

\subsection{Sample, data collection and analysis}

Mombasa County was chosen to carry out the study based on cluster sampling and simple random sampling where all 47 counties were clustered together and simple random sampling used. Mombasa was picked at random from a list of 47 counties. To select Coast general hospital simple random sampling was used to select the hospital, where all hospitals were written on a piece of paper and Coast general hospital picked at random. Questionnaires were prepared and hand delivered to each respondent by the researcher. The respondents comprise nurses in different departments. The respondents were given the questionnaire and each given 20-30 minutes to fill in the questionnaire; upon which questionnaires were collected and put in an envelope and sealed. Data collection took 2 weeks to complete due the number of respondents. On average about 8 respondents filled the questionnaire per day. The response rate was $61 \%$. Data analysis started with data cleaning and use of SPSS version 22 and pearson moment correlation was used to show the strength of the relationship and chi square to show relationship among variables. A significance level of $\mathrm{p}<0.05$ was used.

\subsection{Ethical considerations}

Permission was also sought from the institution to carry out research in their facility. All those participating in the study had to have signed an informed consent form agreeing to voluntarily take part in the study. Confidentiality and anonymity were maintained by ensuring participants do not include any identifying data on the questionnaire. Questionnaires were stored in a locked cabinet and the researcher was the only one with access to the questionnaires. The respondents were free to withdraw from the study without victimization.

\subsection{Results}

A big question is how do we motivate employees? Three motivational factors were investigated Job attributes, remuneration and coworker factors. The response rate was marginally distributed with males being more $(51.0 \%)$ than females (49.0\%) mostly due to the increased number of male nurses. The age distribution was: $18.3 \%$ between 18 and 25 years old, 35.6\% between 26 and 35, 34.6\% between 36 and 45, 11.5\% 46 years and above. Most of the respondents, $n=60(75.0 \%)$ indicated having attained a Diploma level, distantly followed by $n=25$ $(14.4 \%)$ having attained a Higher Diploma level while only $n=15(6.7 \%)$ had a Degree and $n=4(1.9 \%)$ a Certificate. 
Table 1 demographic data

\begin{tabular}{|l|l|l|}
\hline Variables & Frequency & $\begin{array}{l}\text { Percentage (\%) } \\
(\mathbf{N}=104)\end{array}$ \\
\hline Gender & & \\
\hline Male & & 51 \\
\hline Female & & 49 \\
\hline Age & & \\
\hline $18-25$ & 12 & 18.4 \\
\hline $26-35$ & 40 & 35.6 \\
\hline $36-45$ & 39 & 34.6 \\
\hline$>46$ & 9 & 10.5 \\
\hline Academic qualification & & \\
\hline Certificate & 4 & 1.9 \\
\hline Diploma & 60 & 75 \\
\hline Higher Diploma & 25 & 16.7 \\
\hline Degree & 15 & 6.4 \\
\hline Length Of Service & & \\
\hline 1-5yrs & 60 & 53.8 \\
\hline 6-10yrs & 12 & 16.3 \\
\hline 11-15yrs & 25 & 20.2 \\
\hline Over 15yrs & 3 & 9.6 \\
\hline Post basic training & & \\
\hline Received training & 86 & 81.7 \\
\hline Haven't received & 28 & 18.3 \\
\hline
\end{tabular}

The table above presents demographic data

\subsection{Job attributes motivators}

It was revealed as presented in table 2 that a majority of respondents $(80.8 \%)$ do not know the organizational goals in their respective facilities; do not have any departmental work related goals/ targets $(77.9 \%)$; are not involved in decision making (72.1\%); and that they are not allowed to perform same task differently $(81.7 \%)$. The finding is of the implication that a majority of nurses do not find their daily tasks challenging as there are no goals or targets to be met. This if not checked my lead to demotivation and lack of creativity and vigor in executing daily tasks. It is important that goals and targets are set to keep nurses motivated to purse and meet targets. Further it is important that nurses are involved in decisions and policies with a bearing on their professional development. This will make them have a sense of ownership and control over their work. They should also be allowed to perform same tasks differently in order to boost their creativity and therefore effective and efficient service delivery.

Table 2. Job attribute factors.

\begin{tabular}{llllc}
\hline & Yes & $\%$ & No & $\%$ \\
\hline Do you know the organizational goals in your facility & 20 & 19.2 & 84 & 80.8 \\
Do you have any departmental meetings & 21 & 20.2 & 83 & 77.9 \\
Are you involved in decision making & 29 & 27.2 & 75 & 72.1 \\
Are you allowed to perform same task differently & 18 & 17.3 & 86 & 81.7
\end{tabular}

The table above shows the job attribute factors

\subsection{Remuneration Factors}

Majority of respondents $n=96(97.4 \%)$ feel they are not adequately remunerated and that there is no provision to make more money on the job $n=96(97.4 \%)$. Probed on how much in their opinion would be adequate, a majority of respondents cited figures between Kshs75,000 and Kshs100,000. A majority further admitted to working in other health institutions to supplement their income $n=55(52.9 \%)$. It was further revealed that a majority of respondents have not pursued any training post training $n=80(76.9 \%)$ and that they have not been deployed to their area of specialization $n=77(74.8 \%)$.It can be deduced from the foregoing finding, that remuneration is generally poor in the study area. The same does not sustain nurses' personal or professional development needs much to nurses seeking alternative health institutions to supplement their income at their respective stations 
Table 3. Remuneration factors

\begin{tabular}{llllc}
\hline & Yes & $\%$ & No & $\%$ \\
\hline Are you adequately remunerated & 8 & 2.6 & 96 & 97.4 \\
Do you have a provision to make more money on the job & 8 & 2.6 & 96 & 97.4 \\
Do you work in other health institutions to supplement your income? & 49 & 47.1 & 55 & 52.9 \\
Have you pursued any training post training? & 24 & 23.1 & 80 & 76.9 \\
Have you been deployed to your area of specialization & 22 & 21.2 & 77 & 78.8 \\
\hline
\end{tabular}

The table above shows remuneration factors

\subsection{Coworker factors}

Most of respondents $\mathrm{n}=79(76.0 \%)$ agree that in their respective departments, nurses work as team and that respective supervisors in-charge promote a conducive environment to work $n=59(55.8 \%)$. It is notable however that a majority have not received any rewards as a department for teamwork $n=98(95.2 \%)$ or any recognition, awards, monies or appreciation for service. Rewards, recognition, awards, monies and appreciation for service are significant work motivators. It follows then that nurses are highly demotivated to keep up teamwork and continue delivering service. The finding is of the implication that whereas a majority of nurses in the study are committed to teamwork and that for the most part a conducive environment for work is provided.

Table 4. coworker factors

\begin{tabular}{lcccc}
\hline & Yes & $\%$ & No & $\%$ \\
\hline In your department do you work as a team & 79 & 76.0 & 25 & 24 \\
Have you received any rewards as a department for teamwork & 5 & 4.8 & 99 & 95.2 \\
Does your supervisor/ in- charge promote a conducive environment to work & 59 & 55.8 & 45 & 43.3 \\
Have you received any recognition, awards, monies or appreciation for service? & 6 & 4.8 & 98 & 95.2
\end{tabular}

Respondents (29.8\%) rate involvement in decision making as the greatest motivating factor, followed by personal improvement $(26.9 \%)$, then appreciation tools (17.3\%) while monetary motivation and appreciation and recognition recorded the lowest at $7.7 \%$ and $2.9 \%$ respectively.

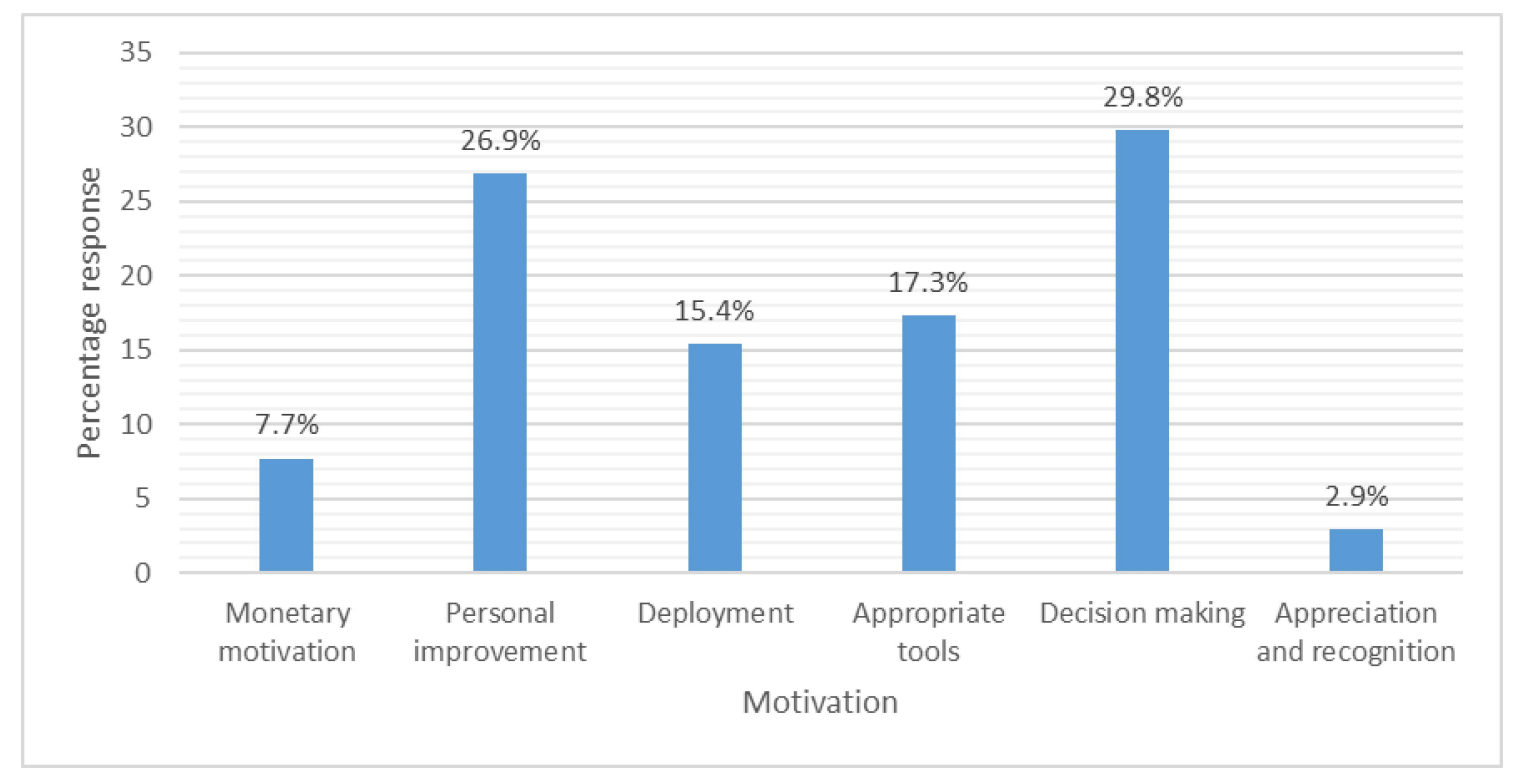

Fig 1. Greatest motivators

\subsection{Performance to patients}

As illustrated in figure 4.16 , a majority of respondents, $93.3 \%$, strongly agree that if they were more motivated they would perform better to patients. 


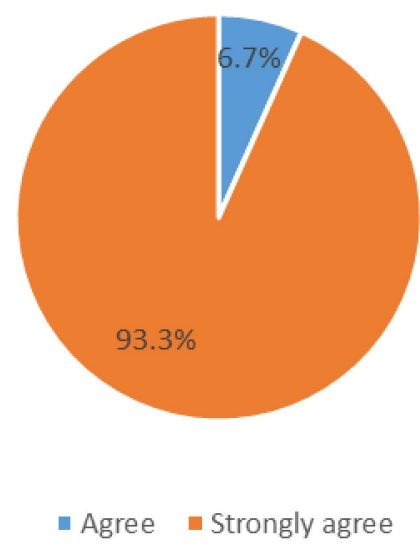

Pearson moment correlation

Fig 2. Performance to patients

A correlation analysis was performed to determine the nature of association between the independent variables.

Table 5 Correlation between the independent variables

\begin{tabular}{lllll}
\hline & & Job-attribute & Remuneration & Co-workers \\
\hline \multirow{3}{*}{ Job-attribute } & Pearson Correlation & 1 & .744 & .642 \\
& Sig. (2-tailed) & & .686 & .162 \\
& $\mathrm{~N}$ & 104 & 104 \\
& Pearson Correlation & 1 & .874 \\
Remuneration & Sig. (2-tailed) & & .97 \\
& $\mathrm{~N}$ & & 104 \\
& Pearson Correlation & & 1 \\
Co-workers & Sig. (2-tailed) & & 104 \\
& $\mathrm{~N}$ & & \\
\hline
\end{tabular}

Job attribute and remuneration showed a positive strong correlation of $r=0.74$.renumeration and coworkers showed a strong positive correlation of $\mathrm{r}=0.87$. Job attributes and coworker showed a strong positive correlation $r=0.64$. A correlation score of $0-0.5$ is considered weak with $0.5-+1$ is considered strong/high positive.

Chi square test

Table 6 Job attributes versus motivation

\begin{tabular}{llll}
\hline & Chi square $\boldsymbol{\chi 2}$ & Df & P-value \\
\hline Authority & 74.678 & 99 & 0.03 \\
Creativity opportunities & 83.965 & 100 & 0.04 \\
Decision making & 97.654 & 65 & 0.00 \\
\hline
\end{tabular}

More nurses preferred decision making $\chi 2=97.654$ at 65 degrees of freedom $(\mathrm{P}=0.01)$ as a motivator compared to authority $\chi 2=74.678$ at 99 degrees of freedom $(p=0.03)$ and creativity opportunities $\chi 2=83.965$ at 100 degrees of freedom $(\mathrm{p}=0.043)$. This shows a statistical significant relationship between job attributes and motivated nurses.

Table 7 Remuneration versus motivation

\begin{tabular}{llll}
\hline & Chi square $\chi \mathbf{2}$ & Df & P-value \\
\hline Salary & 66.674 & 100 & 0.00 \\
Continous proff. training & 84.675 & 103 & 0.04
\end{tabular}

This shows a significant relationship between Remuneration and motivated nurses. Nurses reported salary at $\chi 2$ $=166.674$ at 100 degree of freedom with a $P$ value $(p=0.00)$ as a greater motivator compared to Continous professional training at $\chi 2=84.675$ at 103 degree of freedom with a $P$ value of $(p=0.04)$.

Table 8 Co-workers versus motivation

\begin{tabular}{llll}
\hline & Chi square $\chi \mathbf{2}$ & Df & P value \\
\hline Teamwork & 97.9467 & 78 & 0.04 \\
Appreciation & 73.5466 & 103 & 0.00 \\
Supervisor fairness & 107.4568 & 99 & 0.03 \\
\hline \multicolumn{1}{c}{ Appreciation shows statistical significance with motivating nurses $\chi 2=73.5466$ Df $=103(\mathrm{p}=0.00)}$, \\
supervisor $\chi 2=107.456 \mathrm{Df}=99(\mathrm{p}=0.03)$, teamwork $\chi 2=97.9467 \mathrm{Df}=98,(\mathrm{p}=0.04)$. This shows a significant
\end{tabular}


relationship between co-workers and motivated nurse workforce.

\subsection{Discussion}

The response rate was marginally distributed with males being more $(51.0 \%)$ than females $(49.0 \%)$ mostly due to the increased number of male nurses in Kenya. The age distribution was: $18.3 \%$ between 18 and 25 years old, $35.6 \%$ between 26 and 35, 34.6\% between 36 and 45, $11.5 \% 46$ years and above. Regarding marital status $53.8 \%$ were married and $46.2 \%$ were not married. These two factors play a crucial role in motivating nurses as nurses in the age groups (26-35, 36-45 and 46 years and above) chose to be mostly motivated by job attribute factors like authority, creativity opportunities and decision making. As opposed to the age groups 18-25 whom were more motivated by remuneration and co-worker factor: teamwork. Majority of the nurse have a diploma in nursing as an entry level due to government efforts to improve quality of nursing education as a way to motivate the nurses to grow the profession. Job-attribute factor was second ranked motivator with a positive correlation coefficient with motivated nurse workforce, $(r=0.74)$. Majority $(80 \%)$ of the respondents do not know the organizational goals in their respective facilities and have no departmental work related goals and targets this is inline with a study carried out in Turkana (Ojokaa et al., 2014) nurses do not find their daily tasks challenging as there are no goals or targets and this leads to demotivation and lack of creativity and vigor in executing daily tasks this inturn affects patient outcomes. Remuneration had a strong positive correlation coefficient $(\mathrm{r}=0.87)$ with motivated nurse workforce. This is in line with Dielman et al., (2012) who stated that remuneration is a critical factor of motivation. Most of the nurses feel that continuous professional training is inadequate (76\%). This then ought to be accompanied with posting or deployment to relevant positions and remuneration be observed accordingly. The findings also agree with (Olango \& Gilpon, 2015) who found that $75 \%$ nurses across public hospitals interviewed felt that efforts to improve career development was minimal, more needed to be done to provide an opportunity for nurses to continuously train and improve their knowledge and skills. Co-workers had a strong positive correlation coefficient with $(\mathrm{r}=0.64)$ with motivated nurse workforce. Majority $(76 \%)$ of nurses in the study are involved in teamwork and that for the most part a conducive environment for work is provided. Majority (95\%) of the nurses agree teamwork is not recognized while Majority (93\%) said service is not appreciated. Rewards, recognition, awards, monies and appreciation for service are significant work motivators. The findings are in line with studies carried out in Nigeria by Ditlopo et al., (2008) that established that majority of the nurses also cited recognition and appreciation was important in motivating them even when financial incentives were strained.

\subsection{Conclusion}

Overwhelmingly nurses (94\%) agreed that if they were motivated more they would improve patient care. The study found out that remuneration $\mathrm{r}=(0.97)$, (salary and continuous professional development) was the highest ranked motivator. It can be deduced from the finding, that remuneration is generally poor in the study area. The same does not sustain nurses' personal or professional development needs much to nurses seeking alternative health institutions to supplement their income. It can be deduced that professional trainings are conducted in the study area at considerably favorable pace. This then ought to be accompanied with posting or deployment to relevant positions and remuneration be observed accordingly. This will go a long way in ensuring nurses continue to grow and develop professionally as well as personal and an improvement in the overall satisfaction and therefore retention levels. The second ranked motivator was job attributes $r=(0.46)$ (authority, creativity opportunities, decision making) and the least ranked motivator was co-workers' $r=(0.40)$ (teamwork, supervisor and appreciation).The study can hereby conclude that a majority of nurses do not find their daily tasks challenging as there are no goals or targets to be met. This if not checked my lead to demotivation and lack of creativity and vigor in executing daily tasks. Further it is important that nurses are involved in decisions and policies with a bearing on their professional development. This will make them have a sense of ownership and control over their work. Whereas a majority of nurses in the study are involved in teamwork and that for the most part a conducive environment for work is provided, teamwork and service is not appreciated. Rewards, recognition, awards, monies and appreciation for service are significant work motivators. It follows then that nurses are highly demotivated to keep up teamwork and continue delivering service.

\section{References}

1. Lambrou P, Kontodimopoulou U, Niaken D. (2010). Motivation and job satisfaction among medical and nursing staff in a Cyprus public general hospital, Journal of Human Resource Health, vol. 8, no. 26, pp. 1314: available from http://www.human-resources-health.com ( $1^{\text {st }}$ September 2010).

2. Ministry of Health 2012 Kenya nursing workforce report, Kenya. Ministry of health, viewed $5^{\text {th }}$ May 2016.

3. Ojokaa D, Olango S, Jordan J. (2014). Factors affecting motivation and retention of primary health workers in 3 regions in Kenya Journal of Human Resource Health, vol. 12, no.33 pp. 8-11: available on http://www.human-resources-health.com ( $3^{\text {rd }}$ July 2016 
4. Okelo D, Gilson E. (2015). Exploring the influence of trust relationships on motivation in health sector: systematic review, Journal of Human Resource Health, pp. 7-9 available on http://www.human-resourceshealth.com

5. World Health organization (2013) Transforming and Scaling up Health Worker Education and Training Geneva. World Health Organization pp. 19

6. World Health Organization (2006) Working Together For Health, Geneva, World Health Organization Geneva. World Health Organization pp. 23 